\title{
Efficacy of acute laparoscopic cholecystectomy for acute calculous cholecystitis regardless the length of symptoms
}

\author{
Marek Soltes, Jozef Radonak \\ Department of Surgery, University of Pavol Jozef Safarik in Kosice, Slovak Republic
}

\begin{abstract}
Introduction: Although early acute laparoscopic cholecystectomy within 72 hours is considered method of choice for acute calculous cholecystitis, controversy persists concerning its indication in case of prolonged symptoms.

Materials and Methods: Prospectively run data of patients operated on for acute calculous cholecystitis over period of 3 years in tertiary referral center were analyzed. Acute surgery was performed, regardless of the duration of symptoms, provided that no prohibitive surgical factors were present. Only patients with histopathologically confirmed acute cholecystitis were included in the study. Analyzed parameters included age, gender, preoperative C-reactive protein (CRP) level, time interval from onset of symptoms until surgery, operating time, intraoperative and postoperative complications, conversion rate, length of hospital stay, readmission, and reoperation rate. Analysis was performed on intention-to-treat basis.

Results: Total of 157 consecutive patients, of whom 90 were female and 67 were male, underwent acute cholecystectomy during study period. In all, 130 laparoscopic procedures were performed (83\%) and there were 15 conversions $(11.5 \%$ ). Mean patient age was $59.15 \pm 13.33$ years (range: $24-83$ years), preoperative $\mathrm{CRP}$ was $57.04 \pm 80.84 \mathrm{mg} / \mathrm{L}$ (range: $0.6-455 \mathrm{mg} / \mathrm{L}$ ), onset of symptoms-operation interval was $81.92 \pm 81.12$ hours (range: 5-336 hours), and operating time was $84.47 \pm 35.35$ minutes (range: $35-270$ minutes). Ten intraoperative complications: 3 cases of bleeding from the liver bed, 5 gallbladder perforations, 1 bile duct injury, and 1 instance of arrhythmia were observed. Four postoperative complications occurred: 1 hemoperitoneum, 1 subhepatic connection, 1 transitory intestinal obstruction, and 1 port site abscess. Mean hospital stay was $6.48 \pm 4.00$ days (range: $3-26$ days). Although 1 reoperation was necessary, there was no readmission.
\end{abstract}

Conclusion: Acute laparoscopic cholecystectomy for acute calculous cholecystitis seems to be effective when performed at experienced center regardless of duration of symptoms.

Keywords: Acute; cholecystectomy; cholecystitis; complications; laparoscopy; treatment outcome.

\section{Introduction}

Acute calculous cholecystitis represents the most common complication of gallstone disease. Relatively high prevalence of the pathology underlines the importance of optimal therapeutic management. Although primary con- 
servative treatment may be justified in selected cases, the principal therapeutic approach is the surgical removal of the infl amed organ by cholecystectomy.

Despite proven superiority of primary surgical approach compared to conservative management for the majority of cases, acute cholecystectomy has not gained complete acceptance in everyday practice. ${ }^{[1]}$ Based on population studies, as many as $41 \%$ of the patients with acute cholecystitis are being discharged without surgery upon primary admission, thus being subjects to interval cholecystectomy during the secondary admission on elective basis. ${ }^{[2]}$

Laparoscopic cholecystectomy in acute cholecystitis is a presumably more difficult procedure compared to elective cholecystectomy due to acute infl ammatory changes in the operating field. It is mainly the fear of increased risk for perioperative complications, higher conversion rates and longer operative times preventing quicker acceptance of the technique. The issue of proper timing of surgical intervention still remains controversial. While early laparoscopic cholecystectomy within 72 hours from onset of the symptoms is considered the optimal indication, there is no consensus concerning the patients with prolonged symptoms. ${ }^{[1]}$ Nevertheless, some limited data suggest that laparoscopic surgical management may also provide favorable results following the interval of 72 hours in experienced centers. ${ }^{[3-5]}$

The aim of the study was to assess the efficacy of acute laparoscopic cholecystectomy for acute calculous cholecystitis in the tertiary referral center with the policy to opt for laparoscopic procedure regardless the time interval from onset of the symptoms.

\section{Materials and Methods}

Prospectively run data of the patients operated on for acute calculous cholecystitis over the period of three years was analyzed to assess the results of acute surgical treatment. Minimum pre-operative work-up included history and physical examination, investigation of infl ammatory markers including C-reactive protein (CRP) and white blood cell count (WBC) and abdominal ultrasonography. Histopathological examination confirming the diagnosis of acute cholecystitis was the criterion to be included into the study.

Primary surgical treatment was indicated regardless the length of the symptoms provided there were no general contraindications to surgery detected. Acute cholecystectomy was performed as early as possible after the clinical diagnosis was set. Laparoscopic procedure was considered a method of choice except for defined contraindications which included diffuse peritonitis, detected common bile duct stones after failure of endoscopic clearance, confirmed biliodigestive fistula, severe coagulopathy, and general contraindications of pneumoperitoneum.

Analyzed parameters included age, gender, pre-operative CRP level, time interval between the onset of symptoms and surgery (in hours), operating time (in minutes-from skin incision to skin suture), intraoperative complications, conversion rate, postoperative complications, length of hospital stay (days), need for readmission and/ or reoperation. Analysis was performed on the intention-to-treat basis.

\section{Results}

One hundred and fifty-seven consecutive patients, of whom 90 were female and 67 male, underwent acute cholecystectomy for acute calculous cholecystitis regardless the length of the symptoms in over three years period. Mean age of the patients was $59.15 \pm 13.33$ years (range, 2483), pre-operative CRP level was $57.04 \pm 80.84 \mathrm{mg} / \mathrm{L}$ (range, 0.6-455), and time interval between the onset of the symptoms and surgery was $81.92 \pm 81.12$ hours (range, 5-336).

\begin{tabular}{|lcc|}
\hline Table 1. Reasons for conversion of acute laparoscopic cholecystectomy & \\
\hline Reason & Number of patients & $\%$ \\
\hline Unclear anatomy & 12 & 80.05 \\
$\quad$ Inflammation in Callot`s triangle & 11 & 73.3 \\
$\quad$ Severe necrotizing cholecystitis & 1 & 6.65 \\
Cholecystogastric fistula & 1 & 6.65 \\
Bile duct injury & 1 & 6.65 \\
Severe arrhythmia & 1 & 6.65 \\
\hline
\end{tabular}


One hundred and thirty patients (83\%) underwent acute laparoscopic cholecystectomy with $11.5 \%$ conversion rate (15 patients). Reasons for conversion are summarized in Table 1.

Mean operating time was $84.47 \pm 35.35$ minutes (range, 35270). Intraoperative complications included major bleeding from the liver bed in 2.3\% (3 patients), gallbladder perforation in $3.8 \%$ (5 patients), bile duct injury in $0.7 \%$ (1 patient), and severe arrhythmia in $0.7 \%$ (1 patient) of the patients. In case of bile duct injury, the operation was undertaken due to failed conservative treatment after two weeks of symptoms. Complete trans-section of common hepatic duct was detected during surgery, confirmed by intra-operative cholangiography and primarily repaired by Roux-en-Y hepatico-jejunal anastomosis.

Four major complications occurred in the postoperative period $(3 \%)$, consisting one haemoperitoneum due to bleeding from duodenal serosa, one subhepatic collection, one transitory intestinal obstruction, and one abscess at the port site. Reoperation rate was $0.7 \%$ (1 patient-bleeding from the duodenal serosa) and there was no readmission and mortality. Mean hospital stay was $6.48 \pm 4.00$ days (range, $3-26$ ).

\section{Discussion}

Policy to indicate acute laparoscopic cholecystectomy in patients with acute calculous cholecystitis regardless the length of the symptoms may be a matter of discussion. It is obvious that acute infl ammation in the operating field makes any surgical procedure more complex, thus imposing higher potential for complications, bile duct injuries being the most cumbersome. ${ }^{[6]}$ Traditional concept of interval laparoscopic cholecystectomy within four to twelve weeks after conservative treatment is based on the assumption that acute infl ammation would resolve, thus making the surgical procedure less risky. Nevertheless, such an approach faces at least three principal problems: possible failure of conservative treatment, risk of recurrent symptoms/complications in the interval to definitive surgery, and increased overall costs.

Conservative treatment may probably fail more frequently than anticipated. Meta-analysis of five randomized trials comparing acute versus interval laparoscopic cholecystectomy for acute cholecystitis has revealed cumulative risk of $17.5 \% \cdot{ }^{[5]}$ As prolonged infl ammatory process not responding to antibiotic therapy progressively worsens, it is not surprising that subsequent emergency laparo- scopic cholecystectomy due to local or systemic infl amatory complications may require conversion in up to $45 \%$. ${ }^{[7]}$ Furthermore, the risk of recurrent symptoms and/or complications within the interval to surgery is described to be increasing progressively with the time-being as high as $14 \%$ within six weeks, $19 \%$ within twelve weeks and $29 \%$ within one year after successful completion of conservative treatment. ${ }^{[2]}$ This data explains the observation that 2.4 admissions are necessary on average for the completion of interval laparoscopic cholecystectomy for acute cholecystitis compared to single admission in case that primary surgical approach is chosen. ${ }^{[8]}$ Obviously, prolonged overall hospital stay is linked with increased overall costs.

Above mentioned arguments against interval laparoscopic cholecystectomy would be of limited relevance in case that interval surgery would offer significant benefits over primary surgical treatment. Nevertheless, based on the available evidence, there is no significant difference between acute and interval laparoscopic cholecystectomy for acute cholecystitis in terms of operating time, conversion rate and number of complications, including the risk of bile duct injury. Extensive population study analyzing one million patients undergoing cholecystectomy for acute cholecystitis has concluded that laparoscopic approach results in lower morbidity and mortality rates compared to open surgery, even in the setting of conversion..$^{[9]}$ Therefore, the concept of primary surgical approach represented by acute laparoscopic cholecystectomy appears to be justified, which is also refl ected in international guidelines and recommendations. ${ }^{[1]}$

Although it is obvious that optimal indication for acute laparoscopic cholecystectomy in acute cholecystitis is as early after the onset of symptoms as possible, there is some data available that the time factor may not be a prohibitive parameter for surgery in case that sufficient expertise is available. ${ }^{[3,4]}$ Presented treatment outcomes in our serie of one hundred and thirty consecutive patients with acute calculous cholecystitis treated by laparoscopic cholecystectomy regardless the length of symptoms in the tertiary referral center are favourably comparable to the results accross the literature. ${ }^{[7,9]}$ Acute laparoscopic cholecystectomy thus appears to by highly effective in experienced hands despite prolonged symptoms and particularly complex referral patient population. Nevertheless, further prospective randomized trials with sufficient power are needed to confirm this assumption. 


\section{References}

1. Yamashita Y, Takada T, Strasberg SM, Pitt HA, Gouma DJ, Garden OJ, et al; Tokyo Guideline Revision Committee. TG13 surgical management of acute cholecystitis. J Hepatobiliary Pancreat Sci 2013;20:89-96.

2. de Mestral C, Rotstein OD, Laupacis A, Hoch JS, Zagorski $B$, Nathens AB. A population-based analysis of the clinical course of 10,304 patients with acute cholecystitis, discharged without cholecystectomy. J Trauma Acute Care Surg 2013;74:26-30.

3. Ohta M, Iwashita Y, Yada K, Ogawa T, Kai S, Ishio T, et al. Operative timing of laparoscopic cholecystectomy for acute cholecystitis in a Japanese institute. JSLS 2012;16:65-70.

4. Low JK, Barrow P, Owera A, Ammori BJ. Timing of laparoscopic cholecystectomy for acute cholecystitis: evidence to support a proposal for an early interval surgery. Am Surg 2007;73:1188-92.
5. Gurusamy K, Samraj K, Gluud C, Wilson E, Davidson BR. Meta-analysis of randomized controlled trials on the safety and effectiveness of early versus delayed laparoscopic cholecystectomy for acute cholecystitis. Br J Surg 2010;97:141-50.

6. Chandio A, Timmons S, Majeed A, Twomey A, Aftab F. Factors influencing the successful completion of laparoscopic cholecystectomy. JSLS 2009;13:581-6.

7. Gurusamy KS, Davidson C, Gluud C, Davidson BR. Early versus delayed laparoscopic cholecystectomy for people with acute cholecystitis. Cochrane Database Syst Rev. 2013;CD005440.

8. Chang TC, Lin MT, Wu MH, Wang MY, Lee PH. Evaluation of early versus delayed laparoscopic cholecystectomy in the treatment of acute cholecystitis. Hepatogastroenterology 2009;56:26-8.

9. Csikesz N, Ricciardi R, Tseng JF, Shah SA. Current status of surgical management of acute cholecystitis in the United States. World J Surg 2008;32:2230-6. 